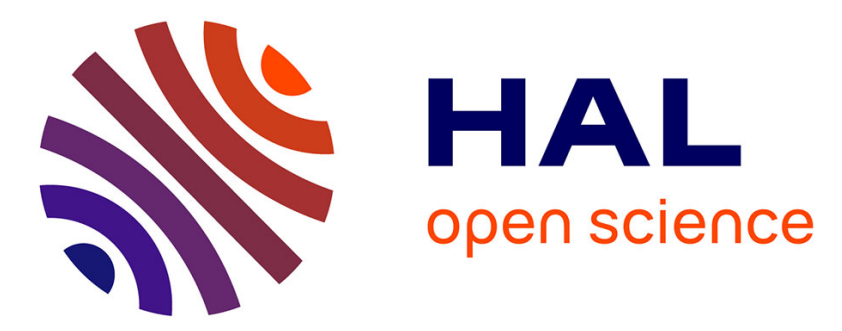

\title{
Toward a new conception of conceptions: Interplay of talk, gestures, and structures in the setting Damien Givry, M.W. Roth
}

\section{To cite this version:}

Damien Givry, M.W. Roth. Toward a new conception of conceptions: Interplay of talk, gestures, and structures in the setting. Journal of Research in Science Teaching, 2006, 43 (10), pp.1086-1109. 10.1002/tea.20139 . halshs-00963628

\section{HAL Id: halshs-00963628 \\ https://shs.hal.science/halshs-00963628}

Submitted on 21 Mar 2014

HAL is a multi-disciplinary open access archive for the deposit and dissemination of scientific research documents, whether they are published or not. The documents may come from teaching and research institutions in France or abroad, or from public or private research centers.
L'archive ouverte pluridisciplinaire HAL, est destinée au dépôt et à la diffusion de documents scientifiques de niveau recherche, publiés ou non, émanant des établissements d'enseignement et de recherche français ou étrangers, des laboratoires publics ou privés.

\section{다)(1) $(5$}

Distributed under a Creative Commons Attribution - NonCommerciall 4.0 International 
Prepared for submission to

Journal of Research in Science Teaching

\title{
Toward a New Conception of Conceptions: Interplay of Talk, Gestures, and Structures in the Setting。
}

\author{
Damien Givry ${ }^{1}$, Wolff-Michael Roth ${ }^{2}$ \\ ${ }^{1}$ University of Lyon $2,{ }^{2}$ University of Victoria
}

Correspondence address: Damien Givry c/o Wolff-Michael Roth, Lansdowne Professor, Applied Cognitive Science, MacLaurin Building A548, University of Victoria, PO Box 3100 STN CSC, Victoria, BC, V8W 3N4 Canada. E-mail:

damien.givry@etu.univ-lyon2.fr c/o mroth@uvic.ca. Tel: 1-250-721-7885.FAX: 1-250$721-7767$.

Filename: Conceptions417.doc

This study arose from the collective work of both authors, funded in part through a research grant from the Social Sciences and Humanities Research Council of Canada (to Roth), which was used to fund a postdoctoral fellowship for Damien Givry. The data employed had been collected by the first author as part of his doctoral dissertation concerning the evolution of high school students' ideas during a unit on gases (e.g., Givry, 2003a, 2003b). 
Running Head: RECONCEPTUALIZING CONCEPTIONS 


\title{
Toward a New Conception of Conceptions: Interplay of Talk, Gestures, and Structures in the Setting
}

\begin{abstract}
A major part of studies about students' conceptions and conceptual change exclusively is based on the analysis language, which is treated as a tool to make private contents of mind public to researchers. Following recent studies that focus (a) on language and discursive practice and (b) on the pragmatics of communication that draws on talk, gestures, and semiotic resources in the setting, we propose a redefinition of the nature of conception. Conceptions are understood as the simultaneously available speech, gestures, and contextual structures that cannot be reduced to verbal rendering because gestures and contextual structures constitute different modalities in the communication. Drawing on data collected during a physics unit about gas taught in French tenth-grade classrooms, we show why an appropriate account of conceptions requires (a) gestures simultaneously produced with talk and (b) identification of the relevant structures in the setting used by the participants as meaning-making (semiotic) resources. We propose to (a) reconceptualize the notion of conception by defining an "idea" as consisting of all relevant semiotic (meaning-making) resources publicly made available by a speaker (talk, gesture, context) and (b) consider conceptual change through the temporal evolution of ideas defined in this manner.
\end{abstract}


"How can I know what I think before I hear what I say" German saying

Since the late 1970's, the conceptualization of student knowledge in terms of conceptions has dominated science education research. There exists a huge body of literature providing evidence for the existence of students' ideas that differ from the standard views of science (e.g., Pfundt \& Duit, 2004). This body of literature also demonstrates the robustness of students' conceptions in the face of efforts to change them. Different models have been proposed for describing the conceptual change students undergo (e.g., Chi, 1991) and some studies identified conditions that would support the evolution of students' initial conceptions towards scientifically correct ones (Strike \& Posner, 1992). Although these studies often vary in the way they go about inducing change, they share two assumptions: (a) conceptions are located somewhere in the mind in the form of mental models (Vosniadou, 2002), p-prims (diSessa, 1993), cognitive elements (Niedderer \& Schecker, 1992), or internal structure (Reiss \& Tunnicliffe, 2001); and (b) language is a means for expressing internal conceptions to the outside world but has little effect on the constitution of the conception.

A different way of thinking about student knowledge was proposed by social (discursive) psychologists (Edwards, 1993) and sociolinguists (Gee, 2004). Accordingly, knowledge is thought of in terms of discursive practices. The notion of discursive practice shifts the emphasis from structure somehow located in the mind to linguistic structures made available in the public arena of classrooms or interviews. Thus, from a discursive perspective, "conception" refers to publicly displayed forms of meaning-making (semiotic) rather than to mental content; furthermore, because there are no private languages (Wittgenstein, 1994/58), what a student expresses is always already contained as a possibility in language so that interviews always also sample cultural ways of articulating the world (Moscovici, 2000). Rather than attempting to construct inaccessible, hidden mental structures, discursive approaches theorize the structure, function, and change of observable talk. The general argument is that we do not know what happens in the students' brain but we have easy access to their talk. Furthermore, most talk in 
everyday situations is produced in real time without prior reflection and editing. Thought is therefore contemporaneous with talk. Focusing on student talk in situation also allows the inclusion of the discourse situation, which has been shown to mediate talk and therefore the conceptions researchers attribute to students (Ueno \& Arimoto, 1993). For example, one recent study (Schoultz, Säljö, \& Wyndhamn, 2001) replicated an earlier one on students' ideas about the earth (Vosniadou \& Brewer, 1992) with the difference that a globe was placed on the desk between interviewer and interviewees. What children said radically changed, which led the authors of the second study to conclude that conceptions should be understood and theorized in terms of situations and language in use.

A body of recent psycholinguistic studies suggests that it is insufficient to analyze student knowing and learning in terms of talk alone. Gestures are an integral part of human expression and provide listeners with aspects of thought that are not (and sometimes cannot be) made available in talk (Goldin-Meadow, 1997; McNeill, 1992). Similar to the early work on conceptions, psycholinguistic studies treat talk and gestures as expressions of underlying cognitive structure and models of meaning. A very different approach is taken by anthropologists and applied linguists, who theorize talk and gestures as these are displayed and used rather than the underlying but inaccessible mental processes (e.g., Kendon, 1997). Even more recent are theoretical and methodological approaches that study thought-in-(inter)action by focusing on the simultaneous display and use of meaning-making resources in talk, gesture, and salient (material) structures in the situation (Goodwin, 2000). Much of this work appears in linguistic journals and the implications for the study of students' conceptions have not been worked out.

The purpose of this study is to argue for an approach that theorizes conceptions in terms of the simultaneous display and use of meaning-making resources in talk, gesture, and salient (material) structures in the situation. Providing empirical examples from a longitudinal study in French physics classrooms, we answer the question "What does the simultaneous analysis of talk, gestures, and relevant elements of the situation provide over and above the analysis of talk alone?" The implications for science teaching are important, because language, gesture, and 
relevant situational structures are directly available to the teacher for adapting instructions in contrast to presumed internal mental structures, which have to be inferred through timeconsuming interpretive work.

\section{Talk, Gesture, Context}

\section{Gesture Domain}

The term "gesture" can be defined as "a movement of part of your body" (Longman Web Dictionary). This definition is imprecise, because it does not specify the part of the body, which is capable of a host of different movements. In our study, the term gesture refers to the movement of hands and arms, and we adopt the distinction between gesture (semiotic hand movements), which appears during communication, and manipulation (ergotic hand movements), which are used to manipulate objects during experiment (Roth, 2003a). Different kinds of gestures have been identified, falling along what is known as Kendon's continuum (McNeill, 1992):

\section{Gesticulation $₫$ Language-like gestures $®$ Pantomimes $®$ Emblems $®$ Sign Languages.}

With the movement from left to right in this continuum, three changes are relevant: (a) the obligatory presence of speech declines; (b) the presence of language properties increases (e.g., grammar); and (c) idiosyncratic gestures (without specific forms) are replaced by sign systems with explicit grammars.

In this continuum, "gesticulation" and "language-like gesture" are idiosyncratic, spontaneous movement of the hands accompanying speech. The difference between the two gesture categories resides in the fact that gesticulation is synchronous with speech, whereas languagelike gestures are grammatically integrated into the utterance taking the place of speech. For example, in the sentence " the molecules ((hand moves up and down next to syringe)) inside the syringe," the hand gesture occupies the grammatical place of a verb, perhaps denoting something 
like "move," "move up and down," or "are pushed." In pantomime the hands depict objects or actions without necessitating speech and without a specific grammatical structure. Emblems are gestures that can be used without concurrent speech and that follow standards of form: showing the middle finger is an emblem used in North-American contexts to insult another person. Finally, sign languages have all the properties of linguistic systems and are generally used without accompanying speech.

In this article, the term gesture denotes gesticulation and language-like gestures. These gestures are differentiated into beat, deictic, iconic, and metaphoric gestures (McNeill, 1992): (a) beat gestures rhythmically accompany speech; (b) deictic gestures denote instances of pointing; (c) iconic gestures are hand-arm movements that depict concrete objects or events; and (d) metaphoric gestures are iconic hand-arm movements that depict abstract objects and events. In the present study, we follow recommendations to focus on deictic and iconic gestures, while including in the latter also metaphoric gestures (Roth, 2003b).

\section{Semiotic Structure in the Situation}

There is a body of research that shows how structures in the setting in which human activities unfold shape and are implicated in practical actions and therefore need to be accounted for in theories of cognition (e.g., Hutchins, 1995). Recent linguistic studies in out-of-school settings show that communication is similarly distributed across practical actors and setting (Goodwin, 2000). For example, to understand the disputes during and over hopscotch games requires simultaneous accounts of meaning-making structures in language, gestures, and the hopscotch field drawn on the parking lot, whereby the specific aspects of the field participants attend are determined as part of the interaction (Goodwin, Goodwin, \& Yaeger-Dror, 2002). Similarly, to understand communication in a scientific research lab required simultaneous accounts of the meaning-making structures in language, gesture, and the physical structures appearing on the shared computer monitor; again, the exact nature of the structures attended to needs to be revealed through careful analysis of interaction participants (Roth, 2004). That is, the ideas that 
the participants in these studies made available to one another include speech, gestures, and perceptually salient elements in the setting. Speech, gesture, and perceptually salient structures in the setting constitute semiotic (meaning-making) resources that cannot be reduced to one another without losing aspects of meaning that arise from the nature of the modality. We understand the perceptually salient elements in the setting as arising from "a dynamic, temporally, unfolding process accomplished through the ongoing rearrangement of structures, in the talk, participants' bodies, relevant artifacts, spaces, and features of the material surround that are the focus of the participants' scrutiny" (Goodwin, 2000, p. 1519).

\section{Research Design}

The purpose of this study is to argue for a different way of conceptualizing conceptions. To exemplify the points we make, we draw on data sources collected as part of the doctoral dissertation of the first author (Givry, 2003a) designed to follow the evolution of students' ideas of the nature of gases. In the following, we describe the study to provide a context for the excerpts from the database used in our argument.

\section{School Context and Participants}

A group of physics teachers and researchers designed the curriculum to be taught over a onemonth period (6 lessons) for students at the upper secondary school level (equivalent to tenth grade [15-year-old students]) in French comprehensive schools. In this study, a specially designed curriculum about the physics of gases was taught and investigated in seven classes of French comprehensive public schools. Two classes with the same teacher were studied more in depth (videotaped interviews and lessons): one contained a majority of students majoring in language and literacy; the other class consisted mostly of students majoring in science. To achieve a representative sample, students from different achievement levels-based on the information obtained from the respective teacher-were asked and agreed to participate. 


\section{Curriculum}

In France, physics is taught using two types of lesson each week: the first lesson type called "Cours" takes place over a one-hour period with all students present; the second type called "TP" takes place over a one-hour-and-thirty-minute period with only half of the students present. Normally, pairs of students conduct experiments in $T P$ lessons and listen to lectures in Cours lessons. However, during the gas curriculum hands-on activities were chosen also for the Cours sessions involving, because of the size of the class, four students in each group.

The unit about gas consisted of six lessons divided into two Cours and four TP. The purpose of the unit was to allow students to use (a) macroscopic variables (pressure, volume, temperature and quantity of matter), and (b) their interpretation at the microscopic level (molecules' collision and velocity) for describing and explaining gas behavior. The unit included four parts: 1 (a) introduction of the microscopic model to describe air contained in an enclosed syringe; (b) use of the microscopic model for describing the mixing of two gases; (c) description of gas behavior in different situations (compressed in a syringe, heated in a bottle connected to a plastic balloon) with the macroscopic variables and with their interpretations at the microscopic level; and (d) establishment of links between the macroscopic variables. Furthermore, the unit is based on a socio-constructivist approach with respect to three main dimensions:

1. By using models, students try actively to establish links between the world of objects and events and the world of theory and model, which supports their understanding (Tiberghien, 2000).

2. By using different representations of the same concept (using formulas, tables, drawings, graphs, natural language), students develop a deeper understanding by establishing links between the representations (Duval, 1995).

3. By beginning with students' pre-instructional language, students can build on what they already know and master to develop more scientific language (e.g., Benson, Wittrock, \& 
Baur 1993; Séré, 1985).

\section{Data Collection}

Different types of data sources were collected including videotaped interviews and lessons and questionnaires sampling student responses to questions about gas behaviors. All in all, the database comprises 420 questionnaires, one-hour taped interviews with 14 students, 48 hours of classroom video featuring the same 14 students, and approximately 160 pages work sheets. The interviews included 14 questions about situations involving every day objects such as balloons, inverted water glass with sugar glued to the bottom to be inserted in a water bath, plastic bags, syringes, and camping cooking equipment. For each situation students, were asked (a) to predict what would happen when the everyday objects were manipulated in a certain way-for example, when the inverted water glass with sugar on the bottom would be dipped into the water bath; (b) to describe what they had perceived after the event was demonstrated or performed by them; and (c) to explain what has happened in the situation. Fourteen students were videotaped during one month of the lessons in classroom with two cameras in static plan without anybody behind and four lapel microphones (one microphone for each student during TP lessons, and one microphone for two students during Cours lessons). An additional camera was used to follow the teacher and the unfolding lesson. The 14 students featured were interviewed prior to and after the unit in videotaped sessions.

\section{Video Analysis}

The videotapes were digitized in QuickTime ${ }^{\mathrm{TM}}$ format; a video analysis software package (Kronos) was used to code the video.2 For the present study, 70 video extracts were selected; all make salient the concurrent use of speech, gestures, and semiotic structures in the setting and therefore support our argument that the concept of conceptions ought to be rethought. We began by conducting tentative individual analyses. Following the precepts of Interaction Analysis 
(Jordan \& Henderson, 1995), we then met repeatedly to view the video clips and to discuss our emergent assertions. These assertions were tested in the entire data set. The video extracts were discussed in a group of ten researchers with different background (science of education, philosophy, sociology, psychology, dentistry) and in informal groups composed of two or three researchers in our group. All extracts given in this article were analyzed by a minimum of three researchers until a common agreement about the interpretation was established. This kind of collective interpretation necessitated making explicit our criteria used to interpret the video, and to put these criteria in our transcription.

\section{Talk, Gestures, and Semiotic Resources in the Setting}

In this section, we present our argument in terms of three assertions, which we exemplify with episodes from our database. The three assertions related to our research questions are:

1. Gestures constitute different kinds of meaning-making (semiotic) elements; therefore, we cannot solely analyze students' talk to find out about the ideas they express.

2. Gestures are polysemic; consequently, we cannot analyze gestures without considering the gestures in their own right rather than translating them into words.

3. Talk and gestures presuppose elements of the situation, which can constitute the major part of students' explanations; consequently, we cannot analyze communication independent of the semiotic resources that partially constitute it.

In the following sections, we present case studies to elaborate each assertion. Our analyses of the talk-gesture-relevant elements relations reveal patterns that are consistent with and therefore confirm similar patterns observed in this database. For each case study, we have sufficient data to substitute the examples several times over with other examples. We chose the specific ones because they are particularly suited for the didactic function that any argument has in communicating a novel ideas to colleagues.

\section{Role of Gestures in Communication}

Gestures are an integral part of human expression and provide listeners with aspects of thought that are not (and cannot be) made available in talk. In other words, talk and gestures are 
two different semiotic resources, which express different aspects of some meaning whole. In this section we show how attending to gestures creates new meaning whole. Our examples show that there are situations where talk cannot be understood without gesture: an essential aspect of a meaning whole may therefore be contained in gestures, which, because of structural differences, cannot be (easily) rendered by translation into language. More generally, then, part of the meaning whole is lost when analysts consider only talk in the study of student conceptions. To illustrate how gestures create different meaning wholes, we selected a video extract from an interview. We first analyze the talk by itself and move to a second analysis of the same verbal transcript with gestures added.

\section{Case study 1: Gestures create different meaning}

Gestures have a perceptual quality that makes them distinct from words, which name concrete objects, events, and concepts. This different quality constitutes a different type of resource for making meaning. This can be seen in Episode 1 involving the student Anne and the interviewer during a 30-minute interview. At the moment of the episode, the conversation pertained to the question was, "What is the distribution of the molecules in three balloons?" given that the first was filled with air, the second with cooking gas (in French, the butanepropane mixture used to cook is referred to as "gaz"; in this article we denote it with the term "cooking gas"), and the third with helium.3

\section{Episode 1:}

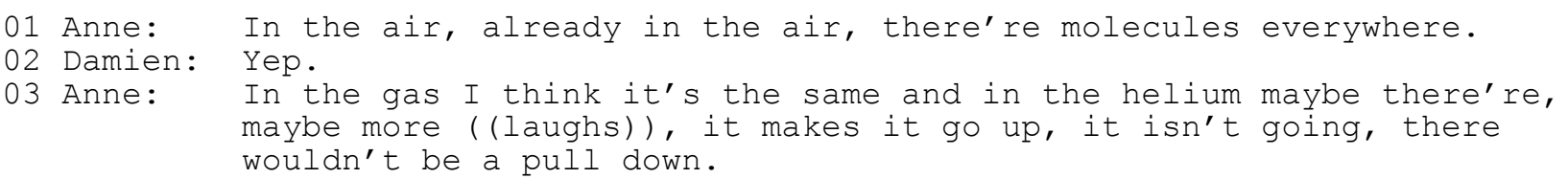

Anne utters, "in the air, there' re molecules everywhere" (turn 01). In this sentence, it remains

3 The second author, fluent in English and French, translated all transcriptions into equivalent English. The following transcription conventions are used: ((laughs)) - transcriber's comments are enclosed in double parentheses; [, ] - square brackets indicate where speech and gestures overlap; - (n-dash) - indicates that an utterance or word stopped short before a completion was evident; (1.0) - time in tenth of a second; (?) - each word that could not be identified is indicated by a question mark in parentheses; : - colon indicates a lengthening of a phoneme by about 0.1 seconds. 
unspecified whether the air is contained in the balloon or the air is contained in the room. However, because the question is about the distribution of molecules in the balloon, we may interpret this sentence as saying that the molecules are everywhere in the air-filled balloon. When Anne says, "in the gas I think it's the same" (turn 03), we may interpret this as suggesting that the molecules are also everywhere in the cooking-gas-filled balloon (in French, the butanepropane mixture used to cook is referred to as "gaz," that is, gas). Finally, concerning the molecules contained in the balloon full of helium, we may interpret her utterance, "in the helium maybe there're, maybe more" (turn 03) as saying that there are more molecules in the heliumfilled balloon. Anne justifies this explanation by saying that the balloon of helium goes up (turn 03). To summarize our interpretation of the student's answer, the molecules are everywhere in the air-filled balloon and in the cooking-gas-filled balloon. However there are more molecules in the helium-filled balloon. This difference seems to be justified by the fact that the balloon of helium goes up when the others go down. How does this interpretation change if we now also consider the gestures that accompanied the talk?

In the following, we enhance part of the preceding transcription (turn 01) by including Anne's gestures.

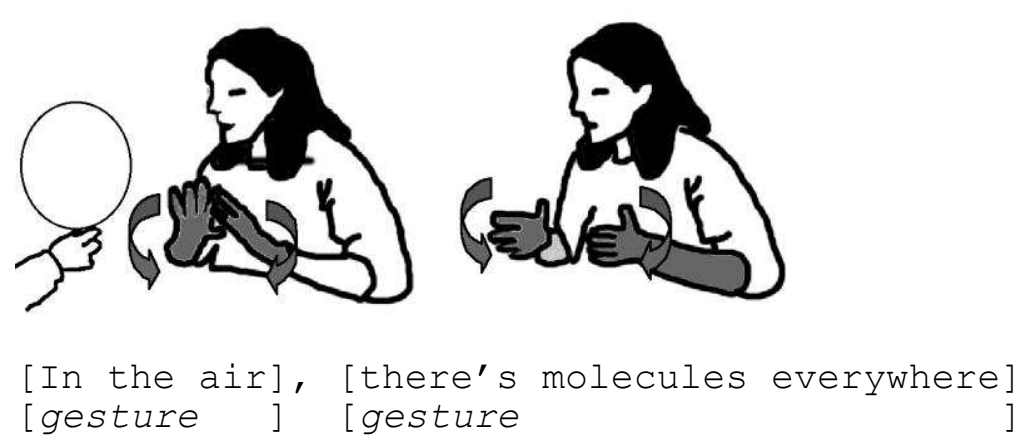

This transcription shows how Anne moves her hands downwards and inwards describing a circle ("circle" is an observation description rather than a description of Anne's intended action). The text between brackets synchronizes talk and gesture. Anne makes the same gesture twice, once while saying "in the air" and another time while uttering "there's molecules everywhere." In her 
talk, the molecules of air are distributed everywhere and the gesture, which can be seen as two hands moving on the surface of a spherical object. However, by saying "in the air" and doing the gesture simultaneously, Anne may specify to be talking about the air-filled balloon held by the interviewer, which allows us to see her gesture as an imagistic rendering of the balloon. "There's molecules everywhere + [content, form of gesture]" can be understood (which requires hearing and seeing) as the molecules are everywhere in the balloon. However, gestures constitute a different mode than words. If the student had wanted to use words, we assume she would have done so. Therefore, to extract her explanation (conception) from the episode, we propose to use the representation "everywhere + [content, form of gesture]" as rendered in the revised transcription. In this way, analysts avoid the danger of over- (and mis-) interpreting gestures, which therefore are taken as aspects and representations of meaning in their own right and which cannot be replaced by words without loss.

The following transcription constitutes an enhancement of a different part of Episode 1, where Anne talks about the distribution of the molecules contained in the cooking-gas-filled balloon (turn 03). The gesture shown in the two plates (hands move downwards and inwards on a circular trajectory) is repeated three times.
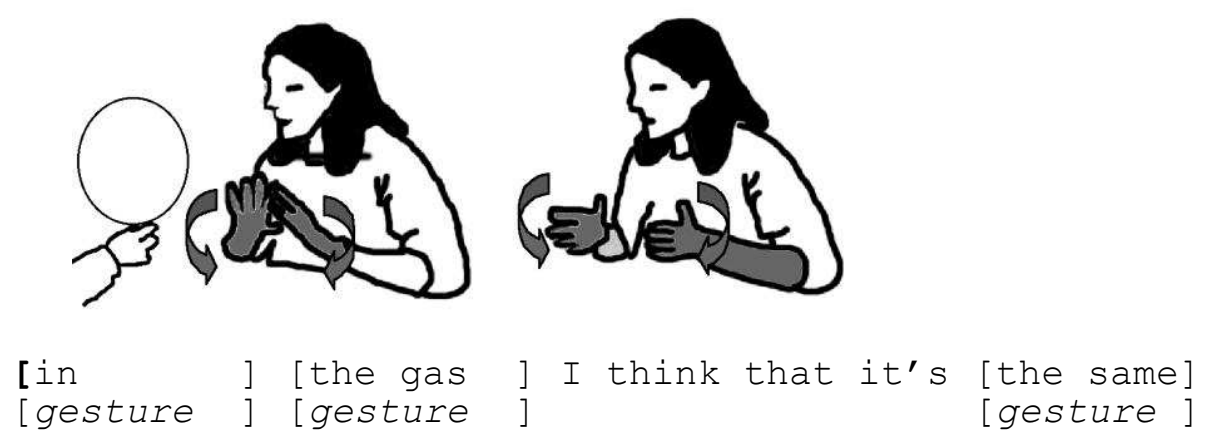

The occurrences of the gesture are synchronized with the utterance of "in," "the gas," and "the same." Here, "the gas" probably refers to cooking gas (butane/propane mixture). According to the preceding sentence, where she says that the distribution of molecules is everywhere, "the same" may refer to the same distribution. Furthermore, the utterances "in" and "the gas" are ambiguous, because they may refer to the inside of the balloon without specifying if the gas is 
inside or outside the balloon. Given that Anne was currently answering the question about the distribution of molecules inside the balloon, we may understand that the molecules are everywhere when the gesture is not considered. However, the gesture can be seen as clarifying some points. By enacting a gesture that has a form similar to the shape of the balloon synchronously with the utterances "in" and "the gas," the communication (which has to be heard and seen) can be interpreted to be about the gas, which is in the balloon. By enacting the same gesture, Anne explicitly provides a gesture-based link between the different elements of her speech.

Anne produces a different, two-part gesture while talking about helium (turn 03). Anne first moves her right hand up and then rotated it. The following transcript includes the gesture:
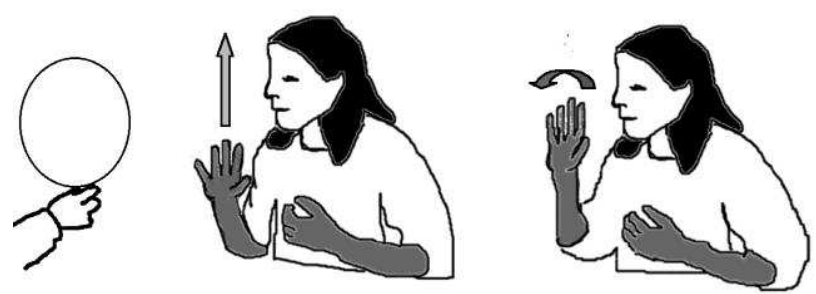

$\begin{aligned} \text { and in the helium } & \text { [maybe there are], maybe more } \\ \text { [gesture } & \end{aligned}$

This two-part gesture can be interpreted in different ways: indeed it could mean that something is (a) going up, (b) going up and spreading out, or (c) moving from left to right. Anne may be communicating that there are more molecules in the balloon full of helium. The utterance "in the helium" may pertain to the helium-filled balloon, and the utterance "there are, maybe more" may refer to the number of molecules. Taken together, the simultaneous production of utterance (i.e., "maybe there are") and gesture, the content of the communicative act may be interpreted differently. The utterance, "maybe there are, maybe more" may pertain to the distribution of the molecules contained in the balloon full of helium, and the gesture may provide an image of how the molecules are distributed in the balloon. In fact, the first part of the gesture may suggest that the molecules are near the top of the balloon and the second part may be understood as a specification that they are spread out inside and near the top of the balloon. In this way, Anne 
may have communicated mean that there are more molecules near the top of the balloon. This new interpretation is very different from the precedent one with talk only (there are more molecules in the helium-filled balloon).

Other interpretations are possible. For example, if the gesture was understood to pertain to the movement of the helium-filled balloon, Anne would have communicated that there are more molecules in the balloon full of helium. However, three different elements seem to be showing that this gesture cannot refer to the balloon. First, Anne speaks about molecules not the balloon. She does not communicate, "“maybe there are in' + gesture," but she only says, "maybe there are, maybe more." Second, the gesture is composed of two continuous movements. The first part may describe the fact that the balloon of helium goes up, but the second hand movement does not correspond to a "normal" movement of helium-filled balloon. Third, when Anne talks about something going up, she makes another gesture, which is moving only upwards without turning from left to right as in the following transcript.

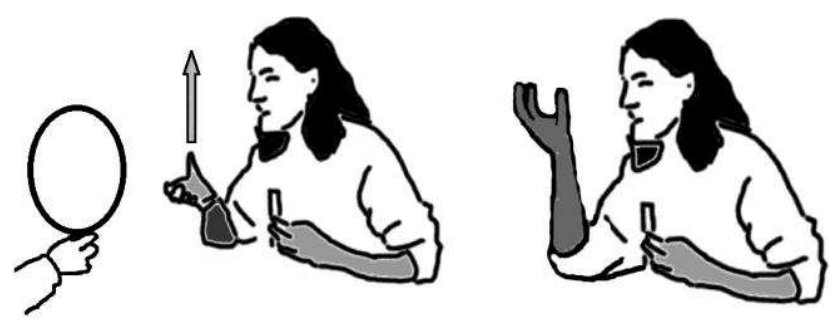

[it's making it go up], it isn't going, there wouldn't be a pull down [gesture

These different points make it likely that the gesture can be glossed as having the molecules as its content. Consequently, Anne possibly articulates that there are more molecules on the top of the balloon full of helium. This interpretation is different than the one based on talk alone; the gesture therefore changes the meaning whole. The major part of the communication (the localization of the molecules) is conveyed only in her gesture. In this interpretation, what Anne articulated (her conception) differs from the teaching content, which portrays gases as occupying the entire space and are distributed everywhere in a closed container. Anne can be said to use the distribution of gas (rendered in gesture) to explain why the helium-filled balloon rises whereas 
the air- and cooking-gas-filled balloons fall.

Our analysis of the transcription with the addition of gesture shows that talk and gesture convey a different meaning whole, and, concerning the helium-filled balloon, the gestures articulate the larger part of the whole. In this case, Anne's utterances cannot be understood independently of the gestures. More strongly said, the gestures radically change how the communication is interpreted. We show how this interpretation depends on a verbal rendering of student gestures. However, a verbal rendering constitutes a translation (Janvier, 1987), which, inherently, involves treason and misses the meaning (Eco, 1984). Such considerations ultimately lead us to suggest that conceptions include speech and gestures, and neither express the other in a faithful manner.

\section{Polysemy of Gestures}

Gestures are polysemic, that is, there is no unique way to interpret and translate them into verbal terms. Furthermore, gestures are topological (i.e., have spatial characteristics) and imagistic in nature and therefore inherently different from words, which are typological, naming objects and concepts (Lemke, 1999). Here we show that (a) gestures cannot be interpreted outside the speech situation in which they occur and (b) gesture cannot be simply rendered in verbal terms.

\section{Case study 2: Gestures cannot be interpreted independent of their speech situation}

This episode was recorded during the third lesson of the unit during a Cours. There are four students working together, including Anne, Ellen, Marie, and Adele. Students have been asked (a) to connect a syringe to a pressure gauge and note the displayed values, (b) to respond to the question, "Using the macroscopic model of gas to tell what will be the value of the pressure, if we connect the syringe to the pressure gauge as in the following drawing (Figure 1)?," and (c) to push the piston while watching the pressure levels displayed by the gauge. 


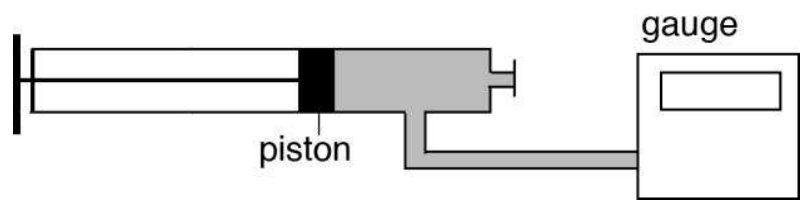

Figure 1: Syringe connected side to a pressure gauge

The four students talk about the questions trying to find out what they have to do. During this discussion student Anne makes a gesture in which the fingers and thumbs of the right hand are brought together as follows:
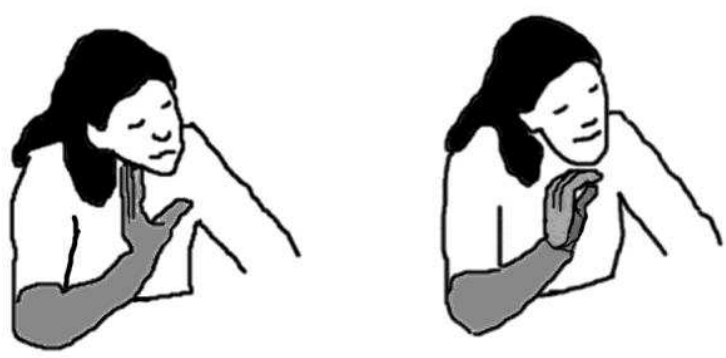

The gesture can be translated differently into language: (a) something is brought together, (b) something is tightened, or (c) something is compressed. The interpretation of the gesture may change with the subject of the sentence while the student speaks about air, syringe, or molecules. Further, any verbal description will fail to render the dynamic aspect experienced by the producer, and the topological aspect produced both for the recipient and producer of the communicative act. Without attendant talk, we cannot ever be sure how to gloss a gesture in verbal terms. This example shows that we cannot analyze gesture without the talk. Let us take a look at the same situation but including the talk produced simultaneously with the gesture.

\section{Episode 2}

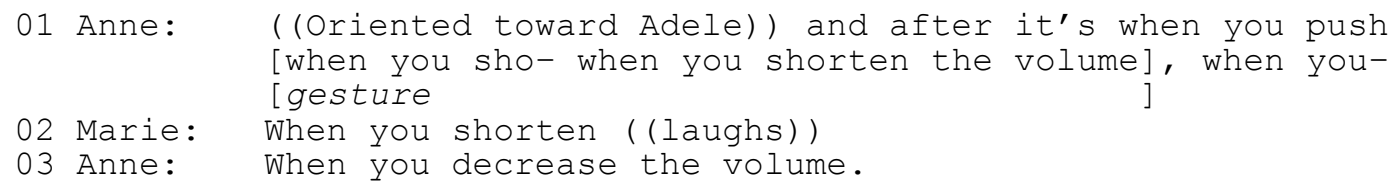

Before this episode, Anne explained to Adele what they have to do during the task. At the beginning, Anne continues her explanation (turn 01), but it appears to be about the second part of the task. She specifies that this manipulation involves decreasing the volume of the syringe (turn 01), and at the same time she produces the gesture that brings together thumb and fingers. Marie 
mocks Anne's use of the expression "to shorten" (turn 02). Anne changes the word now using the expression "decrease" (turn 03). Here, Anne makes the gesture while uttering "you shorten the volume," as rendered in the following transcription, but not while uttering "you decrease the volume" (turn 03).
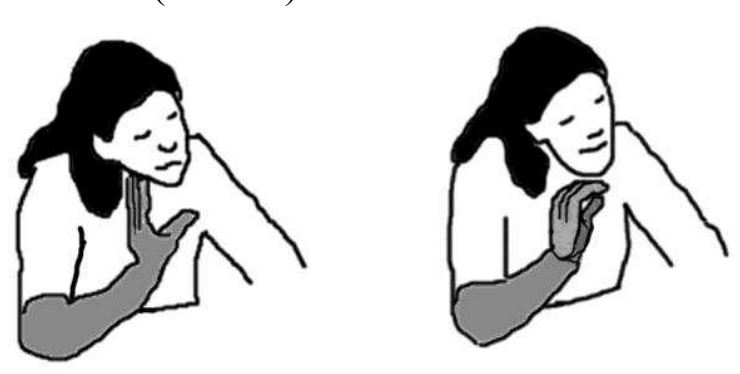

[when you sho- when you shorten the volume] [gesture

One might be tempted to gloss the gesture as "making smaller" or "decrease" the volume of the syringe. If gestures were like words, Anne would be expected to mean the same thing were she to use the gesture again. However, as we show in the next case study, the same gesture has to be glossed differently to make any sense in other parts of the unit.

\section{Case study 3: Different meanings for the same gesture during a one-hour lesson}

During the third lessons of the teaching unit about gas, Anne makes at different moments the same gesture, which seems to correspond to the action of bringing together her fingers (see above). However, we provide some evidence that the sense of the gesture according to her talk changes with changes in the questions students work on.

About eleven minutes into this Cours-type lesson, Anne produces the gesture for the first time; the gesture might be verbally rendered as "to decrease the volume." Four minutes later, she produces the same gesture twice during a 1.0-second pause in speech and in the process of articulating, "air compresses itself," while attempting to answer the worksheet question, "In your opinion, what does the air act into a syringe when its pressure increases?"

\section{Episode 3:}

01 Anne: The action of the air on the inside walls, when you push

02 Marie: Okay well.

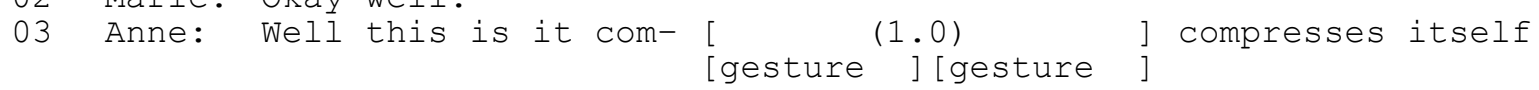


04 Marie: the air compresses itself and uh and it uh b'tch I'm unable to speak

Anne talks about the action of air in the insides (turn 01). She later explains that something compresses itself (turn 03). To refer to this something, Anne uses in the original French video (turn 03) the feminine pronoun "elle," which may have molecule (a female noun) as its reference. In French, air is masculine; one has to use the reflexive pronoun "il" to refer to it. However, many French students appear to use the feminine pronoun to refer to air (Séré, 1985). This makes it also probable that the "elle" (translated by "it") reflexively indexes air (turn 03). Marie explicitly talks about "the air," which "compresses itself" (turn 04). During the interactions following Episode 3, Anne never gives a sign that she disagrees when Marie talks about air being compressed and she never talks about molecules. This makes it probable (though not certain) that words and gesture in turn 03 provide us with a verbal and imagistic description of air that compresses itself. This sense differs from the action of decreasing the syringe volume used by Anne during Episode 2. That is, in the course of four minutes, the same gesture has been repeated but as part of the communication of a different meaning whole.

There is more, for thirty seconds later while working on the same question, Anne reproduces the gesture, but again as part of a communicative act with a yet another sense.

\section{Episode 4:}

$\begin{array}{ll}01 & \text { Anne: and what (?) } \\ 02 & \text { Marie: and exerts a pressure on the inner walls- a stronger pressure } \\ 03 \text { Anne: if it [presses itself], it [exerts a pressure everywhere] } & \text { [gesture }\end{array}$

Here, the students are discussing air. Marie suggests that air exerts a pressure on the inner walls (turn 02). Anne uses again the reflexive pronoun "elle," which we translate as "it" to refer to something that presses itself, and exerts a pressure everywhere (turn 03). During this turn, the same gesture appears in two communicative acts of different (verbal) senses. First, she articulates through talk and gesture an explanation that may be glossed as "air presses itself," which is a statement about the state of air and is similar to the sense in the preceding example, "the air compresses itself." Second, she articulates an explanation that might be rendered as "air exerts a pressure everywhere in the syringe," which would constitute a sense different from the 
previous case, for it concerns the action air does onto something else. An alternative hypothesis of the function of the gesture in this situation derives from a different theoretical approach, whereby it would have the sole purposes of facilitating word retrieval (Hadar \& Butterworth, 1997), an hypothesis that cannot be rejected in the present situation given the placement of the gesture with respect to the verbal utterance in the communicative act as a whole. In fact, the hypothesis may receive further support from a subsequent episode (Episode 5), where the gesture is repeatedly produced while the students are searching for appropriate words.

About eighteen minutes after Episode 4, Anne reproduces the gesture as part of a description of molecule behavior while attempting to respond to the task, "Propose a microscopic interpretation of the action of gas in the inner walls of the syringe, when its volume decreases." As the transcript shows, the gesture is produced as part of attempting to produce or remember a specific word.

\section{Episode 5:}

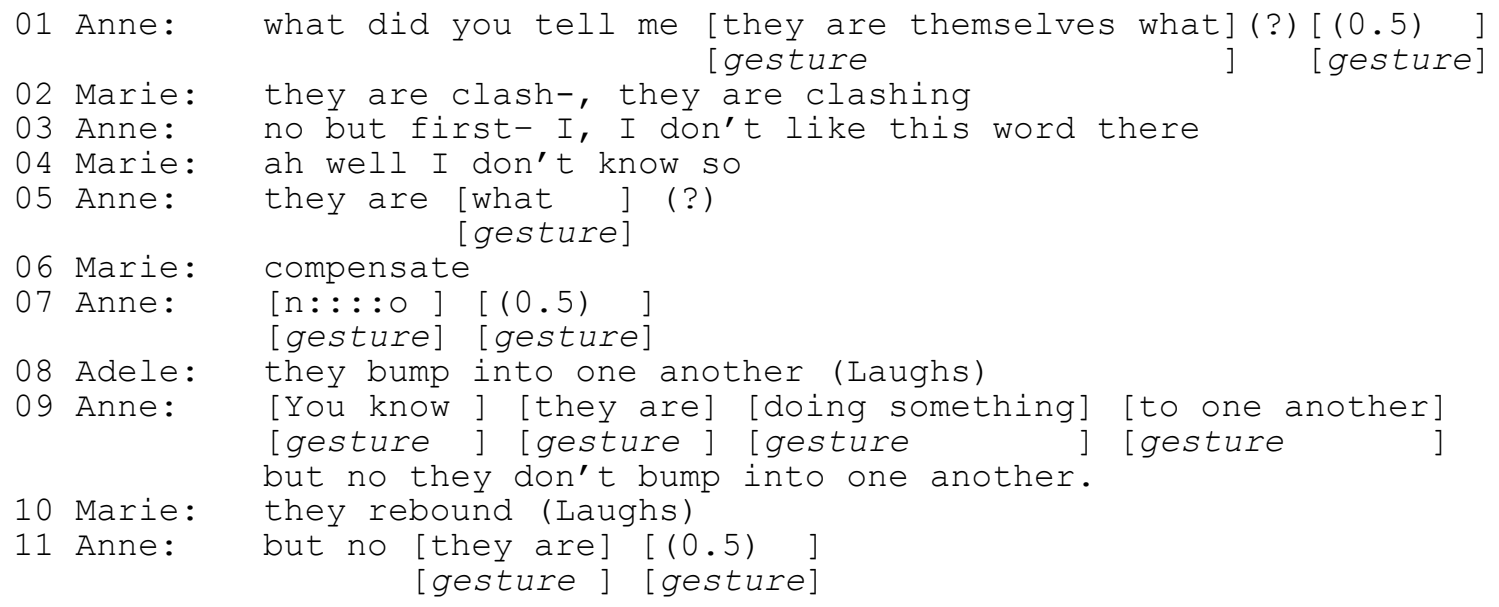

Here, Anne asks Marie to reproduce a previous comment about the behavior of the molecules when the volume of a syringe decreases. Marie proposes that the molecules "clash" (turn 02), but it is not the word Anne appears to be looking for. Anne continues asking her peers, repeating the gesture several times (turns 05, 07, 09). They respond (turns 06, 08, 10), but Anne is not satisfied. Here, the gesture takes the place of a word, perhaps a word she does not remember but knows to exist. 
In the episodes rendered here, a translation of the gesture into the verbal modality would lead us to attribute very different senses to the same gesture. In each case, the situated sense would be associated with the concurrent or surrounding verbal utterance. Furthermore, the same gesture appears to have very different functions, sometimes replacing a word, sometimes occurring concurrently with words, and sometimes simply generating activity that aids in word retrieval. A different approach would be not to translate the gesture and to accept word and gesture as two different aspects of the same communicative act that cannot be reduced to one another. That is, the communicative act constitutes the minimal unit of analysis (McNeill, 1992), and rendering the gesture in verbal terms inherently changes what is being expressed. The conception that would be ascribed to the student would therefore exist in multimodal form, and would have to be researched as a complete unit. Given that most conscious thought is imagistic in nature (Damasio, 2000), such an approach may turn out to be more fruitful.

\section{Structures in Setting as Semiotic Resources}

The preceding subsections show that participants or analysts cannot understand communicative acts without accessing the simultaneously produced gestures. The examples show that gestures in themselves do not lend themselves well to verbal rendering, in part because they are polysemic, in part because translation into words inherently belies the topological and dynamic nature of what is expressed. This suggests that talk and gesture are parts of the same unit of analysis but cannot be reduced to one another. Consequently, researchers interested in students' conceptions ought to construct inscriptions forms that render what students communicate concurrently in the two different modes rather than privileging the verbal mode. In this way, talk and gesture together constitute a minimal psychological unit (Vygotsky, 1962), in which each part contributes to the meaning whole but in different inherently contradictory ways: Gestures are global and synthetic, whereas talk uses segmentation and linearization to form a hierarchy (McNeill, 1992).

Recent research suggests, however, that the unit argued for so far in itself is not sufficient for 
describing situated communication-interaction participants actively use structures in the setting (e.g., grids, fields, and shape of a hopscotch field or the different images from a microscope displayed on a computer screen) as semiotic (meaning-making) resources in their communication (Goodwin, 2000; Roth, 2004). To understand what is being communicated, these semiotic resources need to be known and attended to even though they are not rendered in verbal form. In fact, rendering them in verbal form may falsify what has been said for the same reasons that a verbal rendering of a gesture inherently constitutes an act of treason. Sometimes these resources are pointed to gesturally or verbally (this, that, here), sometimes rendered topologically in iconic gestures. Especially differences in verbal and gestural pointing suggest that the semiotic resources being referred to are not easily rendered in verbal terms and possibly cannot be rendered at all; pointing explicitly brings aspects of the setting into the communication where they have their own meaning-making function that cannot be reduced to words. In this section, we provide examples to support the claim that semiotic resources in the setting need to be part of the unit of analysis and therefore, the way conceptions are represented. Deictic (pointing) gestures are one means of explicitly correlating the three aspects of this newly defined unit of analysis; indexical verbal tokens ("here," "this," "these," or "that") constitute another tool for achieving the same purpose.

\section{Case study 4: Students' use of semiotic resources in the setting}

To illustrate the role of the semiotic resources in the setting, we first analyze the transcription containing talk and gesture, and move to a second analysis of the same transcript to which relevant elements have been added. Based on this second analysis, we articulate the role of semiotic resources in the setting during students' interaction, especially: (a) how students incorporate the semiotic resources in the setting as an integral part of their explanation and (b) how students change modality to articulate their explanations. We draw the episode from a TP lesson, in which, students have been asked (a) to state hypotheses about the possibility of using a syringe to add air to an air-filled bottle and water to a water-filled bottle (b) to propose an 
experiment using the materials at hand to test their hypothesis.

Just before the Episode 6, Ellen explained that it is impossible to add air to an air-filled bottle. Anne disagrees and proposes to show that she can add air to an air-filled bottle.

\section{Episode 6:}

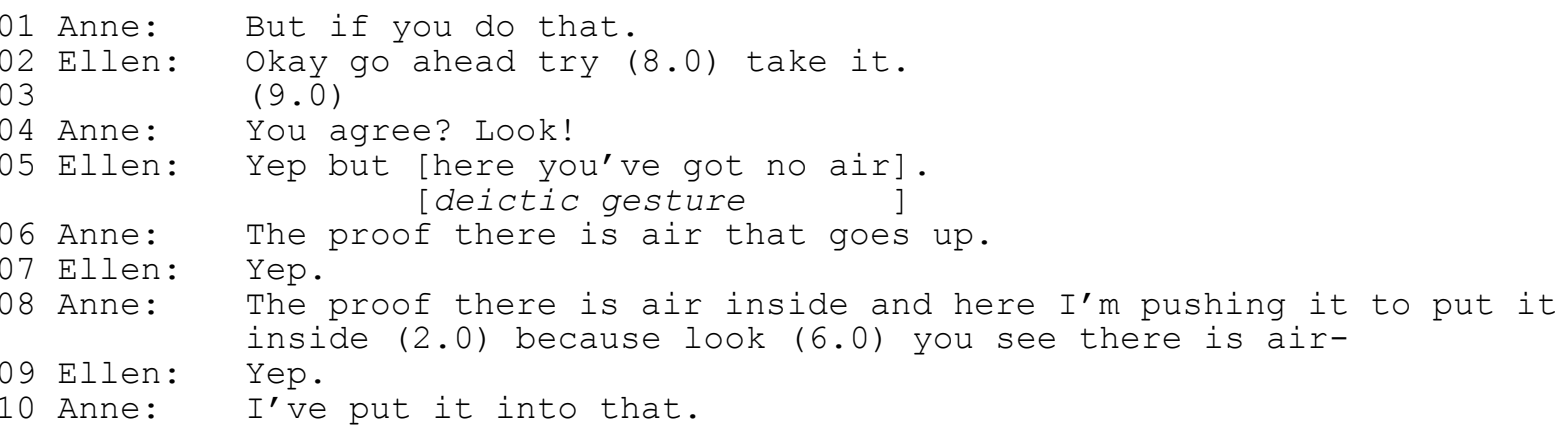

Anne proposes to do something (turn 01), her utterance uses the deictic word "that" but we cannot know what she means without the elements of the setting that the verbal index mobilizes. Ellen proposes to Anne to do it (turn 02) and offers something to Anne. We do not know what it is, but it may be the syringe or the bottle. Afterwards Anne does something during a nine-second period and says, "You agree? Look!" The transcript does not provide any information to know with what she is agreeing (turns 03,04). Ellen responds, "here you've got no air" and at the same time points to something (turn 05). Her talk and gestures give few if any clues to know what elements she is talking about. It could be the air, in the syringe, bottle, or room. Anne seems to use the fact that something is going up (we can suppose that is probably the piston of the syringe) to prove that there is air (turn 06). And she continues (turn 08) by arguing that she is pushing air (possibly with the syringe) to put air inside (possibly inside the bottle), she possibly refers to the same phenomena at the end of the sentence: "because look ... you see there is air" (turn 08) and "I've put it into that" (turn 10). Once again we cannot be sure what is being communicated.

During this episode, Anne tries to justify to Ellen that it is possible to add air to a bottle already filled with air. For that, she refers to different elements of the situation to support her explanation. In fact, her explanation consists of the words, gestures, and the semiotic resources in the setting readily available to all participants. How does this interpretation change if we now 
also consider the semiotic resources in the setting revealed by students during the interaction? During this episode, students use setting-related semiotic resources in each utterance (except turns 07, 09). We suggest that (a) students use semiotic resources in the setting as integral elements in their communication and (b) semiotic resources can change in time.

\section{Role of semiotic resources in communication}

In Episode 6, Anne first connects the syringe on the bottle and simultaneously says, "but if you do that" (turn 01). Ellen then pours the water from the bottle and gives the empty bottle to Anne saying, "take it" (turn 02). Anne connects the syringe with the bottle, pushes the piston, the piston then goes up pushed by the air contained in the syringe and the bottle, and Anne

disconnects the syringe from the bottle (turn 03). Anne says, "You agree? Look!" (turn 04). The following transcript renders the situation including gestures and the apparent semiotic resources in the setting.

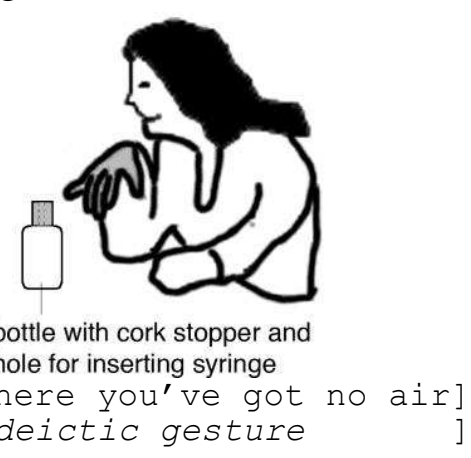

Ellen says, "Yep but here you've got no air," while pointing in the direction of the open bottle. To understand Ellen's communication, we need to simultaneously analyze the three modalities (talk, gestures, semiotic resources in the setting). In which sense does Ellen utter, "here you've got no air." We may seek recourse to her gesture, but does she index the interior of the bottle, the bottle in general, the top of the bottle, the air in the bottle, or any other aspect relating to the bottle? Further, Ellen's deictic gesture cannot be analyzed without the semiotic resource (glossed as "open bottle") that it both refers to and which constitutes its own communicative modality. This action (glossed as "pointing to the direction of an open bottle") cannot be understood without the talk, because it may refer to the bottle, to the air in the bottle, 
or to the cork stopper with a hole in the center. The different elements of the bottle, which may be indexed by this action, support our choice that describing the semiotic resources in the verbal form may falsify what has been performed. To make sense of Ellen's communicative act, we need to analyze at the same time what she expresses through three modalities (talk, gestures, and semiotic resources). If we do not gloss the gesture and the bottle in verbal terms but render them in the way available to others in the situation, that is, in image form, the transcription retains the inherent interpretive flexibility of the communicative act with which all participants and analysts have to deal.

The role of semiotic resources in the setting and interpretive flexibility are also present in the immediately following situation, where Anne pushes on the piston of the syringe connected to the bottle, and the piston goes up. Anne suggests, "the proof there is air that goes up" (turn 06). Ellen seems agree (turn 07). Anne continues, “the proof there is air inside and here I'm pushing it to put it inside" while pushing on the piston of the syringe (first part of the sentence turn 08). We render the situation in the following transcription.

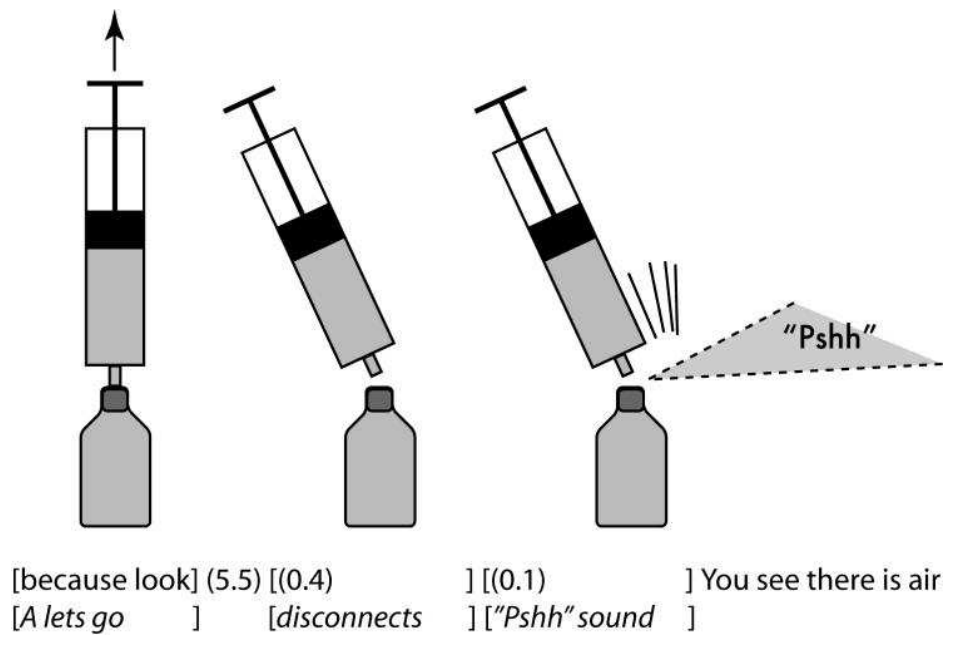

Anne lets go of the piston, which bounces back while she says, "because look." A little later (5.5 seconds), she disconnects the syringe from the bottle, which results in a sound here glossed by "Pshh." She says, "You see there is air."

This communicative act cannot be understood merely on the basis of talk and manipulation, 
alone or in combination. We need to look how Anne articulated and coordinated relevant semiotic resources. By saying "because look" as the first event unfolded (glossed as "the piston goes up"), Anne makes relevant to Ellen (and therefore to the analyst) that this event justifies the statement that air can be added to a bottle already filled with air. In this case, the major part of her explanation is expressed by a structure in the setting, glossed as the piston bounces back. But we do not know whether Ellen sees the piston as bouncing back, she may see it as going up or may be focusing on the expanding air. What ever is salient, it is something to be seen, "because look," something present to Anne in perceptual rather than verbal terms. Any verbal description (i.e., gloss) therefore translates and therefore falsifies the situation for "everything is untranslatable" (Derrida, 1998, p. 57). Translation of the untranslatable into language leads to the hegemony of language, which "remains at work in the culture, effacing the folds and flattening the text" (p. 40). To deal with this quandary in the articulation of student conceptions, we propose that the relevant structures in the situation are represent in the transcript in the same perceptual modality that characterizes their presentation to the participants - the way it is rendered it the drawing rather than in the verbal transcript of Episode 6. The arguments in this situation are not expressed in words alone, but by allowing relevant aspects of the setting stand for themselves. By saying "you see there is air," Anne makes salient the sound glossed as "Pshh" as part of her proof that she added air to the bottle using the syringe.

In this example, the major part of Anne's conception is expressed in and through the semiotic resources in the setting. Anne actively makes these resources part of the communicative act rather than using a verbal description. At the same time, she does not exactly outline (as if naming) which aspect of the setting is relevant. We therefore suggest that her "conception" is better expressed in terms of our expanded transcription than by a translation of perceptual elements and gestures into words, neither of which is verbally represented in the mind (Damasio, 2000). 


\section{Change in the use of semiotic resources}

In the preceding sections of this article, we show that students articulate their explanations in and through different expressive modalities, each with its own characteristic qualities, possibilities, and constraints. Any conception they have therefore requires a rendering of these qualities, because, as shown in neuroscientific research, these are differently represented in the brain: the environment is tracked by means of cognitive indices (Ballard, Hayhoe, Pook, \& Rao, 1997), gestures are represented in the motor cortex and perceptual memory, and language largely in the areas named after Wernicke and Broca (Damasio, 2000). The semiotic resources articulated, however, do not have stable senses but change even within short periods of time, which makes categorical inferences about the (verbally expressed) conception of a student a hazardous project.

Our example unfolds just after Ellen proposes trying to add air to the bottle already filled with air (Episode 6, turn 02). The following transcript renders the events during the nine seconds in the turn 03 and Anne's subsequent communication (turn 04).
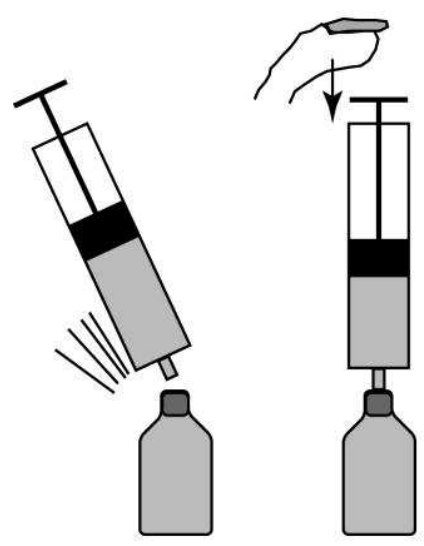

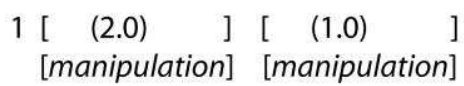

2 (5.0) You agree? Look!

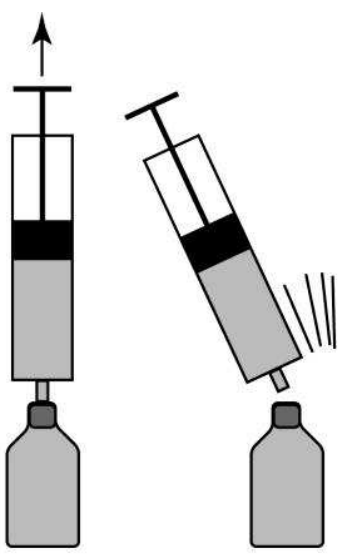

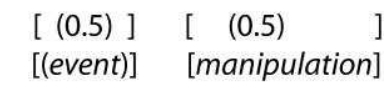

Here, Anne connects the syringe with the bottle and pushes on the piston. The piston bounces back and she disconnects the syringe. Anne waits for five seconds and says, "You agree? Look!". By saying "You agree?" Anne assumes that her peers have perceptually available the same 
semiotic resources that are available to her; by inviting them to "Look!," Anne actively draws their attention to the semiotic resources available. However, these resources are the very event that the conversation is about. These resources therefore do not refer to something else but stand for themselves; they do not have to be mentally represented but are tracked, as cognitive scientists showed, by systems of mental pointers (Ballard et al., 1997). The communicative act, however, which involves Anne articulating something for someone else, requires the analysis of all semiotic resources that participants inherently attend to. Looking at this example, therefore, we have to acknowledge that Anne communicates in three modalities simultaneously, although these modalities are associated with different qualities. For example, words and gestures draw attention to themselves; some of the structures in the setting draw attention only after being pointed to by verbal or gestural means. Gestures and setting have perceptual qualities that words other than onomatopoeia (e.g., pronouncing "Pshh" gives us a sound that is like the one heard by the four students) do not have. This is also evident from the immediately following events. Ellen says “yep but here you've got no air" (turn 05) while using deictic gestures to refer to the open bottle. The following transcript renders the perceptual aspects of the moment.

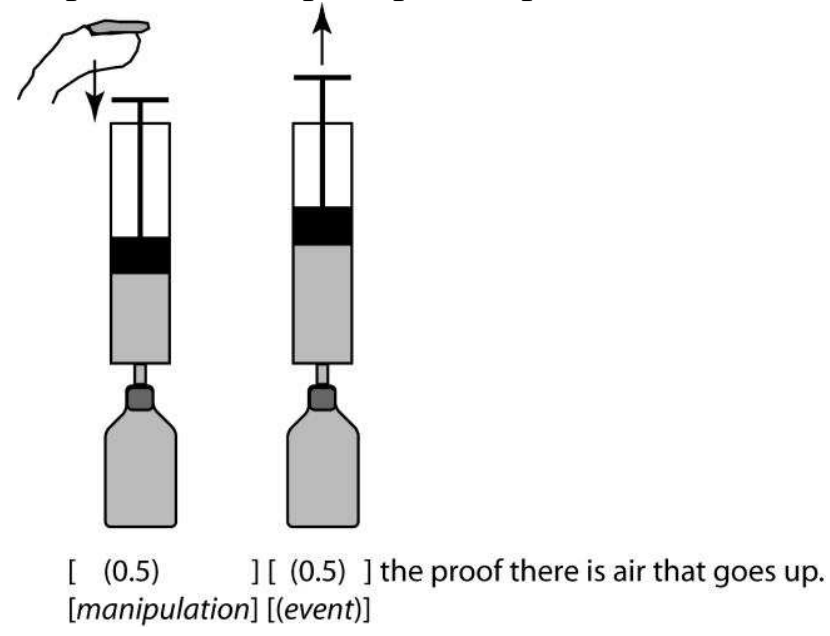

Anne pushes on the piston of the syringe connected with the bottle, then lets go of the piston, which bounces back up. Anne comments, "the proof there is air that goes up." Here again, part of Anne's proof is provided in and through semiotic resources other than words and, here, gestures. That is, it was up to Anne's peer to isolate the relevant meaning-making structures in the 
situation and to understand them as part of her communicative act. In fact, the "proof" was provided entirely in sensorimotor and perceptual terms; verbal means were used retroactively to point to the preceding moment as significant. The comparison of the two examples shows that the use of semiotic resources changes in time. Anne's first explanation is essentially expressed by her manipulations, whereas her second explanation is given by words, and the manipulation is used only to refer to the piston.

\section{Discussion}

\section{Reconceptualization Conceptions}

Talk and gesture are used in communication and our examples show that the major part of a communicative act could be rendered in gestures or consists entirely of semiotic resources in the setting. In this case, student's utterance cannot be understood without the contribution of gestures, because the interpretation of gestures changes radically the meaning of the talk. We show that gestures are polysemic and need to be associated with the concurrent or surrounding verbal utterance to be understandable in the meaning whole. Furthermore, we show that gestures in themselves do not lend themselves well to verbal rendering in part because they are polysemic, in part because translation into words inherently belies what has been expressed. This suggests that talk and gesture are parts of the same unit of analysis but cannot be reduced to each other. Consequently, researchers interested in students' conceptions have to construct representations that render what students communicate concurrently in the two different modes rather than privileging one of them, which traditionally is the verbal mode. In this way, talk and gesture constitute a minimal psychological unit (Vygotsky, 1962), in which each part conveys the whole meaning but in different ways: Gestures are global and synthetic, whereas talk uses segmentation and linearization to form a hierarchy (McNeill, 1992). Although psycholinguists have known these facts for some time, science educators have yet account for them in their theories of conceptions and conceptual change (Roth, 2001). 
Our work, however, goes further than what has been outlined so far. Our examples show that this unit is not sufficient for describing situated communication, because during the interaction, participants actively point to or take for granted elements in the setting as semiotic (meaningmaking) resources in their communication. We provide examples in support of the thesis that semiotic resources in the setting need to be part of the unit of analysis and therefore, the way conceptions are represented. Because the nature of these resources is very different that of words, any verbal gloss substantially misses what the setting contributes. Consequently, we propose to redefine a conception by a unit of analysis composed of talk, gesture, and salient semiotic resources in the setting. The different modalities cannot be reduced to one another (i.e., they are differently represented in the brain) and have to be represented by separate and appropriate means. Furthermore, we propose to give a representation of conception that render what students communicate concurrently in different modalities (talk, gestures, semiotic resources in the setting) rather than privileging the verbal mode (Figure 2).

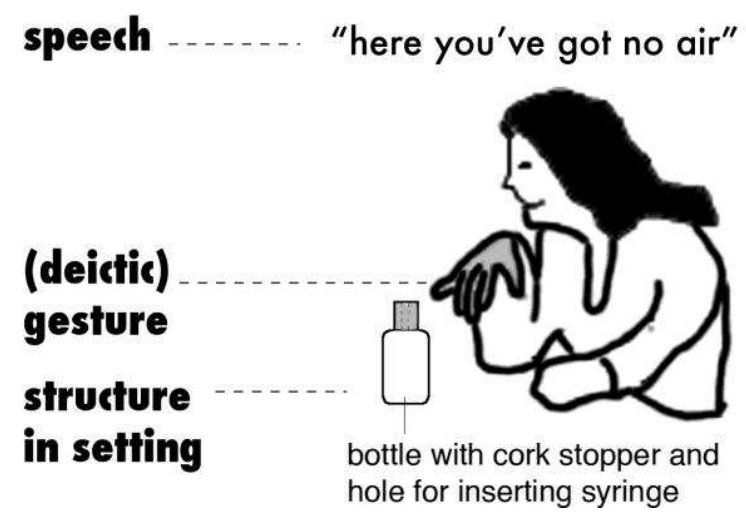

Figure 2. In this example, the proposed conception is expressed simultaneously by talk ("here you've got no air"), gestures (deictic), and semiotic resources in the setting (glossed as "the open bottle").

To prevent confusion with previous definition of conception based on talk only and described exclusively in the verbal mode, we propose to call this unit of analysis an idea. An idea therefore consists of those semiotic resources actually made available by the speaker and used by the listener to make sense: talk, gestures, and semiotic resources in the setting. A proper representation of an idea requires all three mutually constitutive and presupposing - that is, 
dialectically related—modalities (e.g., Figure 2). Consequently, the study of students' conceptions is redefined by the study of how students articulate ideas in and across the three modalities. Some research already shows that prosodic features of speech (intensity, pitch, pitch contours) are further semiotic resources used in classroom conversations (Roth, in press; Roth, Tobin, Carambo, \& Dalland, in press). Future research will show whether and how such additional resources further change our conception of an idea.

\section{Toward a New Way of Describing Conceptual Change}

Based on our definition of an idea, we can describe a new way of thinking about conceptual change: the temporal evolution of speech, gesture, and setting-related semiotic resources and the relationships between different combinations of these modalities (Figure 3).

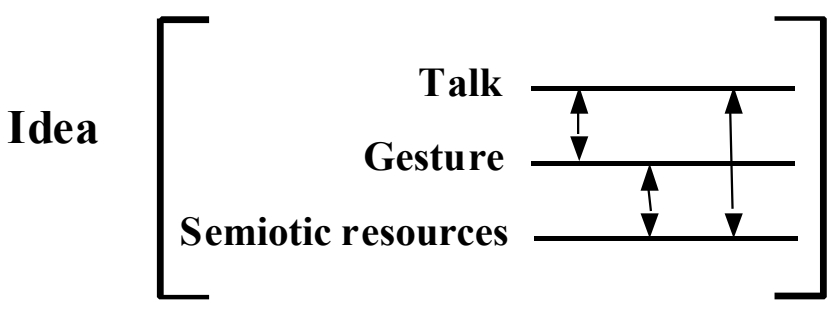

Figure 3: Conceptual change envisaged by the evolution of student's ideas in time through the relationship between talk, gestures and semiotic resources in the setting.

In this way, conceptual change involves different forms of change: (a) evolution in the use of modalities (e.g., use words to describe an objects, instead of designed it by deictic gesture), (b) evolution into a same modality (e.g., use more gestures to describe the same objects), and (c) evolution of the link between different modalities (e.g., the time between talk and gesture decreases). All three types of changes have been reported in the existing research literature but not related to conceptual change.

First, evolution consists in the change of modality (deictic to iconic, or iconic to talk) for expressing "the same thing." For example, some students use deictic gestures, whereas others use iconic gestures to refer to the same medical discourse during a tutorial meeting between medical 
teachers and students (Koschmann \& LeBaron, 2002). Some studies reported evolution in the use of different kind of gesture. Children (from 0 to 2 years) use deictic gestures to refer to material environment, then (from 3 to 5 years) they start to use iconic gestures, and finally start using metaphoric gestures around 6 years old (McNeill, 1985). More recently, some studies in science classrooms show that articulated ideas are first expressed in and through manipulation of materials; the hand movements involved in manipulation then turn into gestures, that is, symbolic expressions (Roth, 2003a). Students then increasingly develop the means to articulate explanations in verbal form (Roth \& Lawless, 2002b). More abstract forms of communication (writing, abstract symbols) are competently used only later in the emerging communicative patterns.

Second, changes can be observed in the use of deictic and iconic gestures and talk. For example, when student use deictic gestures to refer to the top and bottom of a balloon instead of just pointing to the balloon, or use different iconic gestures to apparently describe the same phenomena. During the emergence of language some results show that: (a) students may use different words to refer to the same objects, for example, a group of students refer to an arrow representing the "force" on a computer by using eight different words (Roth \& Lawless, 2002a) or (b) they may use the same word with different meanings, e.g. the same student uses the word "pressure" either as "the action of pushing" which is near to the everyday life use, or as "a physical variable describing a part of the gas state" (Givry, 2003b). These examples illustrate some possibilities of evolution in the same modality of communication.

Third, the links between talk and gestures may change over time. Thus, some studies show that gesture-speech mismatch signals that a child is in a transitional state and is ready to learn (Goldin-Meadow, Alibali, \& Church, 1993). Accordingly, the gesture-speech mismatch disappears after learning suggesting a change in the gesture-speech relation. Other results show that the temporal shifts ("decalage") between talk and associated (i.e., corresponding) gesture decrease when students become more familiar with the explanations, and the amount of gesturing also decreases when they are more familiar to the materials (Roth \& Welzel 2001). 


\section{Coda}

A reconceptualized notion of conception has significant implications for researchers and teachers. The study of students' learning can now be investigated through the relationship between talk, gestures, and semiotic resources in the setting, which form an irreducible unit of communication (analysis). Our proposal has implications not only to the analysis of conceptions and conceptual change but also to the design of curriculum that intends supporting the evolution of students' expressive means. The advantage of the present approach lies in the fact that all relevant elements of thinking about students' conceptions and conceptual change are present in the setting, that is, to students and peers alike. This provides additional means not only for students to express themselves but also for teachers to exemplify scientific forms of expression. We currently do not yet understand the conditions that allow students to change expressive modalities. Because students are ultimately required to express themselves in written form, which is entirely based on the verbal mode, future research is required to study the shift in modality over time.

\section{Acknowledgments}

The authors thank the members of the Cultural-Historical Approach to Thinking Group at the University of Victoria for their critical comments and feedback during the data session. We thank especially Lilian Pozzer-Ardenghi for her precious comments and feedback during the analysis of gestures, Michael Hoffman for the discussions about the theoretical terms used in this article, and JaeYoung Han for his feedback as our manuscript evolved.

\section{References}

Ballard, D. H, Hayhoe, M. M., Pook, P. K., \& Rao, R. P. N. (1997). Deictic codes for the embodiment of cognition. Behavioral and Brain Sciences, 20, 723-767.

Benson, D. L., Wittrock, M. C., \& Baur, M. E. (1993). Students' preconceptions of the nature of gases. Journal of Research in Science Teaching, 30, 587-597. 
Chi, M.T.H. (1991). Conceptual change within and across ontological categories: examples from learning and discovery in science. In R. N. Giere (Ed.), Cognitive models of sciences (pp. 129-186). Minneapolis: University of Minnesota Press.

Damasio, A. R. (2000). Descartes' error: Emotion, reason, and the human brain. New York: HarperCollins.

Derrida, J. (1998). Monolingualism of the Other; or, The prosthesis of origin. Stanford, CA: Stanford University Press.

diSessa, A. (1993). Toward an epistemology of physics. Cognition and Instruction, 10, 105-225.

Duval, R. (1995). Sémiosis et pensée humaine: registres sémiotiques et apprentissages intellectuels. Paris: Peter Lang.

Eco, U. (1984). Semiotics and the philosophy of language. Bloomington: Indiana University Press.

Edwards, D. (1993). But what do children really think?: Discourse analysis and conceptual content in children's talk. Cognition and Instruction, 11, 207-225.

Gee, J. P. (2004). Language in the science classroom: Academic social languages as the heart of school-based literacy. In R. Yerrick \& W.-M. Roth (Eds.), Establishing scientific classroom discourse communities: Multiple voices of research on teaching and learning (pp. 19-37). Mahwah, NJ: Lawrence Erlbaum Associates.

Givry, D. (2003a). Étude de l'évolution des idées des élèves de seconde durant une séquence d'enseignement sur les gaz. Unpublished doctoral dissertation, Université Lumière Lyon 2, Lyon.

Givry, D. (2003b). Évolution du sens que les élèves donnent aux mots dans la construction de connaissance relative aux gaz en classe de seconde. Paper presented at the "Colloque construction des connaissances et langage," Bordeaux (France).

Goldin-Meadow, S., Alibali, M., \& Church, R. (1993). Transitions in concept acquisition: Using the hands to read the mind. Psychological review, 100, 279-297.

Goldin-Meadow, S. (1997). When gestures and words speak differently. Current Directions in 
Psychological Science, 6, 138-143.

Goodwin, C. (2000). Action and embodiment within situated human interaction. Journal of Pragmatics, 32, 1489-1522.

Goodwin, C., Goodwin, M. H., \& Yaeger-Dror, M. (2002). Multi-modality in girls' game disputes. Journal of Pragmatics, 34, 1621-1649.

Hadar, U., \& Butterworth, B. (1997). Iconic gestures, imagery, and word retrieval in speech. Semiotica, 115, 147-172.

Hutchins, E. (1995). Cognition in the wild. Cambridge: MIT Press.

Janvier, C. (1987). Translation processes in mathematics education. In C. Janvier (Ed.), Problems of representation in the teaching and learning of mathematics (pp. 27-32). Hillsdale, NJ: Lawrence Erlbaum Associates.

Jordan, B., \& Henderson, A. (1995). Interaction analysis: Foundations and practice. The Journal of Learning Sciences, 4, 39-103.

Kendon, A. (1997). Gesture. Annual Review of Anthropology, 26, 109-128.

Koschmann, T., \& LeBaron, C. (2002). Learner articulation as interactional achivement: Studying the conversation of gesture. Cognition and Instruction, 20, 249-282.

Lemke, J. (1999). Typological and topological meaning in diagnostic discourse. Discourse Processes, 27, 173-185.

Longman web dictionnary (2004). http://www.longmanwebdict.com/

McNeill, D. (1985). So you think gestures are nonverbal? Psychological Review, 92, 350-371.

McNeill, D. (1992). Hand and mind: What gestures reveal about thought. Chicago: University of Chicago Press.

Moscovici, S. (2000). Social representations: Explorations in social psychology. Cambridge: Polity Press.

Niedderer, H., \& Schecker, H. (1992). Towards an explicit description of cognitive systems for research in physics learning. In R. Duit, F. Goldberg, \& H. Niedderer (Eds.), Research in physics learning: Theoretical issues and empirical studies (pp. 74-98). Kiel: IPN. 
Pfundt, H., \& Duit, R. (2004). Bibliography: Students' and teachers' conceptions and science education. Kiel: IPN.

Reiss, M. J., \& Tunnicliffe, S. D. (2001). Students' understanding of their internal structure as revealed by drawings. In H. Behrendt, H. Dahncke, R. Duit, W. Graeber, M. Komorek, \& A. Kross (Eds.), Research in science education: Past, present, and future (pp. 101-106).

Dordrecht, The Netherlands: Kluwer Academic Publishers.

Roth, M.-W. (2001). Gestures: Their role in teaching and learning. Review of Educational Research, 71, 365-392.

Roth, M.-W. (2003a). From epistemic (ergotic) actions to scientific discourse: Do gestures obtain a bridging function? Pragmatics \& Cognition, 11, 139-168.

Roth, M.-W. (2003b). Gesture-speech phenomena, learning and development. Educational Psychologist, 38, 249-263.

Roth, M.-W. (2004). Perceptual gestalts in communication. Journal of Pragmatics, 36, 10371069.

Roth, M.-W. (in press). Body and emotion in knowing and learning. In J. Kincheloe (Ed.), 19 questions about classroom teaching (pp. ••••••). New York: Peter Lang.

Roth, W.-M., \& Lawless, D. (2002a). Signs, deixis and the emergence of scientific explanation. Semiotica, 138, 95-130.

Roth, M.-W., \& Lawless, D. (2002b). Science, culture, and the emergence of language. Science Education, 86, 368-385.

Roth, W.-M., Tobin, K., Carambo, C., \& Dalland, C. (in press). Coordination in coteaching: Producing alignment in real time. Science Education, $\bullet \bullet, \bullet \bullet \bullet \bullet \bullet \bullet$.

Roth, W.-M., \& Welzel, M. (2001). From activity to gestures and scientific language. Journal of Research in Science Teaching, 38, 103-136.

Schoultz, J., Säljö, R., \& Wyndhamn, J. (2001). Heavenly talk: discourse, artifacts, and children's understanding of elementary astronomy. Human Development, 44, 103-118.

Séré, M.-G. (1985). The gaseous state. In R. Driver, E. Guesne, \& A. Tiberghien (Eds.), 
Children's ideas in science (pp. 104-123). Milton Keynes: Open University Press.

Strike, K. A., \& Posner, G. J. (1992). A revisionist theory of conceptual change. In R. Duschl \& R. Hamilton (Eds.), Philosophy of science, cognitive psychology and educational theory and practice (pp. 147-176). Albany: State University of New York Press.

Tiberghien, A. (2000). Designing teaching situations in the secondary school. In R. Millar, J.

Leach \& J. Osborne (Eds.), Improving science education: the contribution of research (pp. 27-47). Buckingham, UK: Open University Press.

Ueno, A., \& Arimoto, N. (1993). Learning physics by expanding the metacontext of phenomena. The Quaterly Newsletter of the Laboratory of Comparative Human Cognition, 15, 53-63.

Vosniadou, S., \& Brewer, W. F. (1992). Mental models of the earth: a study of conceptual change in childhood. Cognitive Psychology, 24, 535-585.

Vosniadou, S. (2002). Mental models in conceptual development. In L. Magnani \& N. Nersessian (Eds.), Model-based reasoning: science, technology, values. New York: Kluwer Academic Press.

Vygotsky, L. S. (1962). Thought and language. Cambridge, MA: MIT Press.

Wittgenstein, L. (1994). Philosophical investigations (3rd ed.). New York: Macmillan. (Originally published in 1958) 